\title{
RESIDUAL DO HERBICIDA IMAZETAPIR NA CULTURA DO MILHO
}

\author{
Claiton Gomes Santos, Abilio Nobrega Reis, Ana Carolina Ferreira, Renata Pereira Marques \\ Instituto Federal Goiano - IFG, GO. E-mail: santosgomesclaiton@gmail.com
}

\begin{abstract}
RESUMO
Um dos problemas na agricultura moderna é o resíduo de herbicidas na sucessão de culturas, principalmente a cultura do milho em sequência à cultura da soja, mais conhecido como cultura do milho safrinha. A sucessão é uma prática comum dos sistemas produtivos de grãos, visando maximizar os rendimentos das propriedades, sendo que algumas práticas adotadas no manejo da cultura de verão podem afetar diretamente a cultura subsequente. Objetivou-se com esta pesquisa avaliar o efeito residual do herbicida imazetapir, aplicado no cultivo de soja em pré-emergência ou dessecação, sobre a cultura do milho cultivada em sucessão em seus estádios iniciais. Tratou-se de uma experimentação com 5 tratamentos e 4 repetições em delineamento inteiramente casualizado, envolvendo diferentes épocas de semeadura do milho, sendo elas: 90, 105, 120 e 135 dias após a aplicação (DAA) do herbicida imazetapir, e um tratamento controle sem a aplicação do herbicida. Foram analisados a porcentagem fitotoxidade com 7, 14, 21 e 28 dias após a semeadura (DAS), a velocidade de emergência de plântulas, peso de massa de matéria seca da parte aérea e raiz aos 28 DAS. Os tratamentos semeados com 90 e 105 DAA apresentaram efeito de fitotoxidade em todas as avaliações, apresentando também menor peso de massa de matéria seca de parte aérea e raiz, demonstrando assim, efeito residual e influência do herbicida na cultura até os 105 DAA. Com relação à emergência de plântulas, os tratamentos não diferiram entre si.
\end{abstract}

Palavras-chave: plantas daninhas; controle químico; sucessão de culturas; Zea mays

\section{RESIDUAL EFFECTS OF IMAZETHAPYR HERBICIDE IN CORN CROP}

One of the problems in modern agriculture is the residue of herbicides in the succession of crops, mainly the corn crop in sequence to the culture of the soybeans, better known as corn crop. Succession is a common practice of grain production systems, aiming to maximize yields of the properties, and some practices adopted in the management of the summer crop can directly affect the subsequent crop. The objective of this research was to evaluate the residual effect of the herbicide imazethapyr on the cultivation of soybeans in pre-emergence or desiccation on maize cultivation in succession in its initial stages. It was a trial with 5 treatments and 4 replications in a completely randomized design, involving different corn sowing times: 90, 105, 120 and 135 days after application (DAA) of the herbicide imazetapir, and a control treatment without the application of the herbicide. Percentage of phytotoxicity was analyzed at 7, 14, 21 and 28 days after sowing (DAS), seedling emergence velocity, shoot dry mass and root weight at 28 DAS. The treatments sown with 90 and 105 DAA showed a phytotoxicity effect in all the evaluations, also presenting lower weight of shoot and root dry mass, thus demonstrating the residual effect and influence of the herbicide on the crop up to 105 DAA. Regarding the emergence of seedlings, the treatments did not differ.

Keywords: weed, chemical control, crop succession, Zea mays

\section{INTRODUÇÃO}

O Brasil é um dos maiores produtores de milho do mundo segundo o 11 o levantamento (CONAB, 2018), a produção total da cultura foi de 82,1 milhões de toneladas, representando
$35,95 \%$ do total de grãos produzidos no país em 2018. O milho também se destaca como o grão mais consumido globalmente: estima-se que, na safra 2017/18, seu consumo alcançou 1.066,6 milhões de toneladas (FIESP, 2018); sua utilização 
é ampla, abrangendo seu emprego para alimento, assim como para uso industrial e energético.

A produção da cultura em diversas áreas do país está atrelada ao modelo de sucessão de culturas ou de semeadura direta, geralmente posicionado posteriormente a soja, pois permite o aumento de renda da propriedade no mesmo ano e evita que a área agrícola permaneça em pousio (NÓBREGA, 2016).

A utilização de herbicidas em pré emergência com efeito residual, garante uma excelente alternativa de controle de plantas daninhas. Por isso, herbicidas com estas características são amplamente utilizados na dessecação pré-plantio da soja que antecede a "safrinha" de milho (MONQUERO et al., 2008).

Uma das principais dificuldades com a recomendação e aplicação de herbicidas é sobre a dinâmica dos produtos no solo, e os fatores que afetam esta dinâmica (CHRISTOFFOLETI et al., 2005). Por isso o conhecimento das dinâmicas do herbicida no solo e no ambiente é fundamental para escolha do produto correto, sem impacto sobre as espécies de interesse.

O imazetapir é um herbicida seletivo, sistêmico, de ação de pós-emergência apresentado na formulação concentrado solúvel para controle principalmente de plantas daninhas de folhas largas bem como de gramíneas infestantes na cultura da soja e do arroz irrigado (AGROFIT, 2016).

Este é absorvido pelas folhas das plantas daninhas e desta forma transloca-se pelo xilema e floema, acumulando-se nos meristemas de crescimento impedindo a síntese da enzima acetolactato sintase (ALS) que por sua vez participa do processo de biossíntese de três aminoácidos essenciais: valina, leucina e isoleucina. Esta inibição interrompe a síntese protéica que, interfere na síntese do DNA e no crescimento celular (TAIZ; ZIEGER, 2009). Os sintomas mais comuns são cloroses foliar, morte do ponto de crescimento e por fim a morte total das plantas daninhas, que pode ocorrer entre 10 e 20 dias após a aplicação (IMAZETAPIR, 2016).

Diante disso, o objetivo deste trabalho foi avaliar o efeito residual do herbicida imazetapir utilizado no manejo de plantas daninhas aplicados em pré-emergência na cultura da soja, sobre o milho cultivado em sucessão.

\section{MATERIAL E MÉTODOS}

O estudo foi realizado em casa de vegetação situado na zona rural do município de Rio Verde - Goiás, com as seguintes coordenadas geográficas: latitude $17^{\circ} 43^{\prime} 07.0^{\prime \prime} \mathrm{S}$ e longitude $50^{\circ} 59^{\prime} 17.8^{\prime \prime} \mathrm{W}$ a $740 \mathrm{~m}$ de altitude.

Foram utilizados vasos plásticos com capacidade de $8 \mathrm{~kg}$, preenchidos com solo que apresentava granulometria de $56 \%$ de argila, $10 \%$ de silte e $34 \%$ de areia, e as seguintes características químicas: $\mathrm{pH}\left(\mathrm{CaCl}_{2}\right)=4,8$; M.O. $=$ $8,7 \mathrm{~g} \mathrm{dm}^{-3} ; \mathrm{P}=1,5 \mathrm{mg} \mathrm{dm}^{-3} ; \mathrm{K}=7 \mathrm{mg} \mathrm{dm}^{-3} \mathrm{Ca}=$ $0,6 \mathrm{mg} \mathrm{dm}^{-3} ; \mathrm{Mg}=0,2 \mathrm{mg} \mathrm{dm}^{-3} ; \mathrm{B}=0,135 \mathrm{mg} \mathrm{dm}$ ${ }^{3} ; \mathrm{Cu}=0,2135 \mathrm{mg} \mathrm{dm}^{-3} ; \mathrm{Fe}=35 \mathrm{mg} \mathrm{dm}^{-3} ; \mathrm{Mn}=4,7$ $\mathrm{mg} \mathrm{dm}^{-3} ; \mathrm{Zn}=0,1 \mathrm{mg} \mathrm{dm}^{-3} ; \mathrm{CTC}=3,5 \mathrm{mg} \mathrm{dm}^{-3} ; \mathrm{V} \%$ $=55$.

O delineamento experimental utilizado foi o inteiramente casualizado, utilizando o herbicida imazetapir a $1 \mathrm{~L} \mathrm{ha}^{-1}$, equivalente a 106 g i.a. ha ${ }^{-1}$, pulverizado em pré-emergência, e os tratamentos foram os intervalos entre a pulverização e a semeadura do milho $(90,105$, 120, 135 DAA), com quatro repetições.

A aplicação do herbicida em préemergência ocorreu no dia 28 de fevereiro de 2016, utilizando-se um pulverizador costal, pressurizado a $\mathrm{CO}_{2}$ e equipado com um reservatório de 2 litros (modelo NV-02). O equipamento foi regulado para proporcionar um consumo de calda de $150 \mathrm{~L} \mathrm{ha}^{-1}$. A barra de aplicação foi equipada com seis pontas do tipo leque simples "Teejet" XR 11002 distanciados a $50 \mathrm{~cm}$ entre si.

As condições ambientais na hora da aplicação foram favoráveis, com vento na velocidade de $3 \mathrm{~km} / \mathrm{h}$, temperatura de $24^{\circ} \mathrm{C}$, umidade relativa do ar em $78 \%$ e cobertura de nuvens em $80 \%$.

Foi simulado via irrigação de gotejo precipitação de $406,4 \mathrm{~mm}$ em todos os tratamentos antes do plantio, parcelados em 15 vezes. Esse total é o somatório equivalente à pluviosidade que ocorreu no local do experimento segundo dados captados via estação meteorológica na propriedade.

As semeaduras ocorreram 90, 105, 120, 135 DAA, entre os dias 28/05/2016 e 07/07/2016. Utilizou-se sementes do híbrido NS 90 PRO2 da empresa Nidera, classificado como ciclo médio, de aproximadamente 145 dias, devidamente certificadas, livre de impurezas e patógenos. Semeou-se três sementes por vaso. Não foram realizadas adubações e correções do solo antes do plantio. 
O experimento teve início em 28/02/2016 e foi conduzido até o dia 04/10/2016 onde ocorreu a última avaliação em casa de vegetação, seguido de colheita para pesagem e avaliações da massa de matéria seca do último tratamento.

Avaliou-se o nível de fitotoxidade das plantas de milho visualmente aos 7, 14, 21 e 28 DAS, levando em consideração a coloração das folhas, vigor, capacidade de recuperação e danos físicos das plantas, utilizando uma escala percentual onde $0 \%$ significava ausência de sintomas e $100 \%$ significava a morte da planta (SBCPD, 1995).

A massa de matéria seca foi obtida através da pesagem das plantas (parte aérea e raíz) ao final do experimento. Após secagem do material vegetal em estufa de circulação de ar forçado a $60^{\circ} \mathrm{C}$ até atingirem massa constante, os materiais foram pesados utilizando balança analítica de precisão $0,001 \mathrm{~g}$.

Todos os resultados foram submetidos à análise de variância e as médias foram comparadas entre si pelo teste de Tukey a $5 \%$ de probabilidade, utilizando o programa estatístico Sisvar (FERREIRA, 1998). Os resultados referentes aos níveis de intoxicação foram transformados em arco seno $\sqrt{ } \mathrm{x} / 100$.

\section{RESULTADOS E DISCUSSÃO}

Tabela 1. Porcentagem dos sintomas de fitointoxicação de plantas de milho semeadas em solo tratado com imazetapir. Rio Verde, 2016.

\begin{tabular}{|c|c|c|c|c|}
\hline \multirow{2}{*}{$\begin{array}{l}\text { Tratamentos } \\
\text { (dias) }\end{array}$} & \multicolumn{4}{|c|}{ Dias Após Aplicação } \\
\hline & 7 & 14 & 21 & 28 \\
\hline Controle & $0,00 b$ & $0,00 d$ & $0,00 b$ & $0,00 c$ \\
\hline 90 & $55,00 a$ & $45,00 a$ & $30,00 a$ & $17,5^{\mathrm{a}}$ \\
\hline 105 & $48,75 a$ & $27,50 b$ & $25,00 a$ & $12,5 a b$ \\
\hline 120 & $12,25 b$ & $12,50 c$ & $10 \mathrm{~b}$ & $10,00 b$ \\
\hline 135 & $10,00 b$ & $0,00 d$ & $0,00 b$ & $0,00 c$ \\
\hline F Tratamento & $93,74^{* *}$ & $137,77^{* *}$ & $30,44 * *$ & $32,33^{* *}$ \\
\hline CV\% & 21,03 & 19,36 & 38,05 & 34,23 \\
\hline DMS & 11,73 & 7,42 & 11,37 & 6,17 \\
\hline
\end{tabular}

**significativo a $1 \%$ de probabilidade; médias seguidas de mesma letra na coluna não diferem estatisticamente entre si pelo Teste de Tukey $(P \leq 0,05)$.

Com relação aos dados de fitotoxidade observa-se que o imazetapir interferiu de forma negativa do 70 ao 28 dia nos tratamentos 2 (90 DAA) e 3 (105 DAA). Estes resultados corroboram com os encontrados por Dan et al. (2011), que ao avaliarem o efeito residual de herbicidas utilizados em pós-emergência na cultura da soja sobre o milho safrinha detectaram que 0 herbicida imazetapir nas doses de 0,06 e 0,1 kg $\mathrm{ha}^{-1}$ provocaram sintomas de fitointoxicação significativos nas avaliações realizadas aos 7, 15 e 28 dias após a emergência (DAE) da cultura do milho, os maiores percentuais de fitotoxidade foram observados no tratamento $0,1 \mathrm{~kg} \mathrm{ha}^{-1}$, independentemente da época de avaliação, chegando a $18,5 \%$ aos 28 DAE.

Dan et al. (2012), avaliando resíduos de herbicidas utilizados na cultura da soja sobre o milho cultivado em sucessão, verificou que a atividade residual do herbicida imazetapir $0,1 \mathrm{~kg}$ ha ${ }^{-1}$ foi suficiente para causar leve intoxicação às plantas de milho dos 7 aos 28 DAA.

Segundo Ulbrich et al. (2005) o uso dos herbicidas imazetapir na cultura da soja provocou sintomas de fitointoxicação no milho como: estrias com amarelecimento internerval, morte de plântulas e consequente redução de estande. Sintomatologia semelhante foi observada por Dan et al. $(2011,2010)$ ao avaliarem os efeitos de imidazolinonas na cultura do milho, sorgo e milheto. Brighenti et al. (2002), trabalhando com aplicação do herbicida imazetapir na cultura do girassol, verificaram redução na população de plantas de girassol quando realizado a semeadura aos 45 DAA. 
Tabela 2. Emergência de plântulas (dias), massa de matéria seca (g) da parte aérea e raiz de plantas de milho.

\begin{tabular}{llll}
\hline Tratamentos & $\begin{array}{l}\text { Emergência de plântulas } \\
\text { (dias) }\end{array}$ & $\begin{array}{l}\text { MMS parte aérea } \\
(\mathrm{g})\end{array}$ & $\begin{array}{l}\text { MMS raiz } \\
(\mathrm{g})\end{array}$ \\
\hline Controle & 5,00 & $9,70 \mathrm{a}$ & $9,17 \mathrm{ab}$ \\
90 & 5,40 & $3,37 \mathrm{~b}$ & $3,14 \mathrm{c}$ \\
105 & 5,16 & $3,98 \mathrm{ab}$ & $4,18 \mathrm{c}$ \\
120 & 5,00 & $5,27 \mathrm{ab}$ & $7,18 \mathrm{bc}$ \\
135 & 5,00 & $8,21 \mathrm{ab}$ & $14,02^{\mathrm{a}}$ \\
\hline F Tratamento & $0,06^{\text {ns }}$ & $3,93^{*}$ & $16,32^{* *}$ \\
CV\% & 3,98 & 45,20 & 28,50 \\
DMS & 0,38 & 6,22 & 4,84 \\
\hline
\end{tabular}

**significativo a $1 \%$ de probabilidade; *significativo a $5 \%$ de probabilidade; ${ }^{\text {ns }}$ não significativo; médias seguidas de mesma letra na coluna não diferem estatisticamente entre si pelo Teste de Tukey $(P \leq 0,05)$.

Na variável emergência de plântulas não se observou resultados significativos. Com relação às variáveis pesos de matéria seca de parte aérea e de raízes houve uma estreita relação entre os dados observados. (Tabela 2 ).

A semeadura aos 90 DAA apresentou o menor peso de massa de matéria seca de parte aérea, e no tratamento controle observou-se o maior peso, resultados semelhantes foram encontrados por Dan et al. (2012), quando mesmo semeado aos 97 DAA, o milho sofreu redução no acúmulo de massa de matéria seca da parte aérea das plantas, evidenciando a grande sensibilidade da espécie a esses herbicidas.

Pinto et al. (2009), detectou reduções na produtividade de massa de matéria seca do sistema aéreo do milho de 40 e $80 \%$, respectivamente, nos substratos que continham resíduos das aplicações de 100 e 200 g i.a.ha ${ }^{-1}$ de imazetapir + imazapic.

Esses dados vão de encontro com as recomendações feitas por Gazziero et al. (1997) que recomendaram um intervalo de 90 a 120 dias entre as aplicações de imazaquim ou imazetapir para a semeadura do milho. Os demais tratamentos não apresentaram diferenças entre si.

Quanto ao peso das raízes, os tratamentos 2 (90 DAA) e 3 (105 DAA) não se diferiram entre si obtendo os menores pesos observados. Segundo Pinto et al. (2009), a massa de matéria seca de raiz é uma variável que tem se mostrado adequada para avaliar a sensibilidade de plantas à herbicidas do grupo químico das imidazolinonas. Estes resultados encontrados corroboram com dados reportados por Silva et al. (1999), que observaram que $100 \mathrm{~g} \mathrm{ha}^{-1}$ de imazetapir, aplicados à cultura da soja, provocaram inibição de aproximadamente $20 \%$ na massa de raízes do sorgo semeado aos 90 DAA, demonstrando que o sistema radicular dessa planta reflete muito bem a sensibilidade da espécie a esse herbicida.

Para Loux et al. (1989) a maioria dos herbicidas com atividade residual no solo, é muito afetado pelo $\mathrm{pH}$, teores de argila e matéria orgânica do solo. Quando as condições de adsorção do herbicida são favorecidas, ocorre uma queda na sua atividade e mobilidade. Vários estudos têm mostrado que a adsorção de imazetapir aumenta com o decréscimo do $\mathrm{pH}$. Geralmente os herbicidas persistem mais em solos com maiores teores de argila e matéria orgânica e baixo pH de solo (MILANOVA; GRIGOROV, 1996).

Segundo Silva et al. (1998) resíduos de imazaquim no solo prejudicam mais o crescimento do sistema radicular do que a parte aérea de plantas de milho cultivadas após a soja. Dados semelhantes também foram relatados por Shaw e Wixson (1991), em estudos realizados em casa de vegetação, onde observaram que $13 \mathrm{~g}$ i.a.ha ${ }^{-1}$ de imazapic foram suficientes para reduzir o peso fresco e seco das raízes do milho e sorgo.

Os demais tratamentos apresentaram maiores pesos e não se diferiram entre si, incluindo o tratamento controle. Segundo Ulbrich et al. (1998), após 90 dias da aplicação de imazetapir na dose de $80 \mathrm{~g}$ i.a.ha ${ }^{-1}$, ou 122 dias na dose de $160 \mathrm{~g}$ i.a.ha ${ }^{-1}$, ocorre a adsorção de grande parte desse produto tornando o mesmo menos disponível para as plantas.

Corroborando com estes resultados, Gazziero et al. (1997), relataram que, a partir de 120 DAA de imazaquim e imazetapir, as plantas 
de milho não apresentaram dano provocado pelos produtos.

\section{CONCLUSÃO}

O herbicida imazetapir teve efeito de fitotoxidade sobre os tratamentos semeados até os 105 dias após sua aplicação, influenciando negativamente na massa de matéria seca de parte aérea e raiz.

Estes resultados não são suficientes para resultar a uma análise de produtividade, contudo indicam interferência do herbicida nos estádios iniciais das plantas de milho.

\section{REFERÊNCIAS}

AGROFIT. Sistemas de agrotóxicos fitossanitários. Disponível em: <agrofit. agricultura.gov.br/agrofit_cons/principal_agrofit_ cons>. Acesso em: 20 ago. 2017.

\section{CONAB. Décimo Segundo Levantamento de Safra}

17/1. Disponível em:

<https://www.conab.gov.br/info-

agro/safras/graos/boletim-da-safra-de-

graos/item/9760-11-levantamento-safra-2017-

18>. Acessado em: 19 ago. 2018.

BRIGHENTI, A. M.; MORAES, V. J.; OLIVEIRA JUNIOR, R. S.; GAZZIEIRO, D. L. P.; BARROSO, A. L. L.; GOMES, J. A. Persistência e fitotoxicidade de herbicidas aplicados na soja sobre o girassol em sucessão. Revista Pesquisa Agropecuária Brasileira, Brasília, v. 37, n. 4, p. 559-565, 2002. https://doi.org/10.1590/S0100$\underline{204 \times 2002000400019}$

CHRISTOFFOLETI, P. J.; LÓPEZ-OVEJERO, R.F.; NICOLAI, M.; CARVALHO, S.J.P. Dinâmica dos herbicidas aplicados ao solo na cultura da canade-açúcar. Piracicaba: BASF, p. 49, 2005.

DAN, H.A.; DAN, L.G.M.; BARROSO, A.L.L.; PROCÓPIO, S.O.; OLIVEIRA JR., R.S.; ASSIS, R.L.; SILVA, A.G.; FELDKIRCHER, C. Residual activity of herbicides used in soybean agriculture on grain sorghum crop succession. Planta Daninha, Viçosa, v. 28, n. 5, p. 1087-1095, 2010.

DAN, H. A.; BARROSO, A. L. L.; OLIVEIRA JÚNIOR, R. S.; CONSTANTIN, J.; DAN, L. G. M.; BRAZ, G. B. P.; OLIVEIRA NETO, A. M.; D'AVILA, R. P. Seletividade de clomazone isolado ou em mistura para a cultura do algodoeiro. Planta Daninha, Viçosa, v. 29, n. 3, p. 601-607, 2011a.
DAN, H.A.; DAN, L.G.M.; BARROSO, A.L.L.; PROCÓPIO, S.O.; OLIVEIRA JR., R.S.; ASSIS, R.L.; SILVA, A.G.; FELDKIRCHER, C. Atividade residual de herbicidas pré-emergentes aplicados na cultura da soja sobre o milheto cultivado em sucessão. Planta Daninha, Viçosa, v.29, n.2, p. 437-445, 2011b.

DAN, H.A.; DAN, L.G.M.; BARROSO, A.L.L. NETO, A.M.O.; GUERRA, N. Resíduos de herbicidas utilizados na cultura da soja sobre o milho cultivado em sucessão. Revista Caatinga, Mossoró, v. 25, n. 1, p. 86-91, 2012.

FIESP. Safra Mundial de Milho. Boletim informativo, $4^{\circ}$ levantamento do USDA. Disponível em: http://www.fiesp.com.br/indicespesquisas-e-publicacoes/safra-mundial-de-milho2/attachment/file-20180813192126-

boletimmilhoagosto2018/. Acesso em: 20 ago. 2018.

FERREIRA, D. F. Sisvar - sistema de análise de variância para dados balanceados. Lavras: UFLA, p.19 1998.

GAZZIERO, D.L.P.; KARAN, D.; ULBRICH, A. Persistência dos herbicidas imazaquin e imazethapyr no solo e os efeitos sobre plantas de milho e pepino. Planta Daninha, Viçosa, v.15, p.162-169, 1997.

http://dx.doi.org/10.1590/S010083581997000200009.

IMAZETAPIR. Concentrado Solúvel. 2016. Disponível em: <http://www.adapar.pr.gov.br/arquivos/File/defi s/DFI/Bulas/Herbicidas/ZETHAPYR_106_SL.pdf >. Acesso em 12 fev. 2018.

MILANOVA, S.; GRIGOROV, P. Movement and persistence of imazaquin, oxyfluorfen, flurochloridone and terbacil in soil. Weed Research, v. 36, p. 31-36, 1996. DOI: 10.1111 / j.1365-3180.1996.tb01798.x.

MONQUERO, P. A., BINHA, D. P., SILVA, P. V., e AMARAL, L. R. Eficiência de herbicidas préemergentes após períodos de seca. Planta Daninha, Viçosa, v. 26, n. 1, 2008. http://dx.doi.org/10.1590/S010083582008000100019. 
NÓBREGA, A. R. Análise de efeito residual do herbicida imazetapir na cultura do milho. 2016. 22f. Monografia (Curso de Bacharelado em Agronomia) - Instituto Federal de Educação, Ciência e Tecnologia Goiano - Campus Rio Verde, Rio Verde, GO, 2016.

PINTO, J.J.O.; NOLDIN, J.A.; MACHADO, A.; PINHO, C.F.; ROSENTHAL, M.D.; DONIDA, A.; GALON, L.; DURIGAN, M. Milho (Zea mays) como espécie bioindicadora da atividade residual de (imazethapyr+imazapic). Planta Daninha, Viçosa, v. 27, n. spe, p. 1005-1014, Dec. 2009. http://dx.doi.org/10.1590/S0100-

$\underline{83582009000500014 .}$

RUEDELL, J. A. Tecnologia dos herbicidas pósemergente. ICl Agrícola, ano 10, n. 45, Dez. 1991.

SHAW, D.; WIXSON, M. Postemergence combinations of imazaquin of imazethapyr with AC 263, 222 for weed control in soybean (Glycine max). Weed Science, v. 39, p. 644-649, 1991.

SBCPD - SOCIEDADE BRASILEIRA DA CIÊNCIA DAS PLANTAS DANINHAS. Procedimentos para instalação, avaliação e análise de experimentos com herbicidas. Londrina, 1995. v. 1, p. 42.

SILVA, A. A.; OLIVEIRA JR., R. S.; CASTRO FILHO, J. E. Avaliação da atividade residual no solo de imazaquin e trifuralin através de bioensaios com milho. Acta Science, v. 20, n. 3, p. 291-295, 1998.

SILVA, A. A. et al. Efeito residual no solo dos herbicidas imazamox e imazethapyr para as culturas de milho e sorgo. Planta Daninha, Viçosa, v. 17, n. 3, p. 345-354, 1999.

TAIZ, L.; ZEIGER, E. Fisiologia vegetal. 4. ed. Porto Alegre: Artmed, p.820, 2009.

ULBRICH, A.V; BENEDITO, N. R.; DE LIMA, J. Efeito residual dos herbicidas imazaquin e imazethapyr, aplicados na soja, sobre o milho safrinha. Planta Daninha, Viçosa, v. 16, n. 2, 1998.

ULBRICH, A. V.; SOUZA, R.P.; SHANER, D. Persistence and carryover effect of imazapic and imazapyr in Brazilian cropping systems. Weed Technology, v. 19, n. 4, p. 986-991, 2005. https://doi.org/10.1614/WT-04-208R2.1
Recebido para publicação em 10/10/2017

Revisado em 13/08/2018

Aceito em 22/08/2018 